choosing experimental conditions which would tend to suppress free-radical formation and favour ionization.

It has been found that dianisylcarbinyl nitrite, prepared from dianisylcarbinol and nitrosyl chloride in the presence of pyridine, decomposes at room temperature yielding mainly dianisyl ketone ; however, on reduction of the decomposition products with either tin and hydrochloric acia, or iron and acetic acid, a small amount ( 0.8 per cent) of dianisylmethylamine can be isolated as the $\mathrm{N}$-benzoyl derivative, melting point $173-74^{\circ}$ (found: $\mathrm{C}, 76.0 ; \mathrm{H}, 6.26$; $\mathrm{N}, 3.90$ per cent; $\mathrm{C}_{22} \mathrm{H}_{21} \mathrm{O}_{3} \mathrm{~N}$ requires $\mathrm{C}, 76 \cdot 1$; $\mathrm{H}, 6.05 ; \mathrm{N}, 4.03$ per cent), undepressed in melting point on admixture with a specimen obtained by the benzoylation of dianisylmethylamine, melting point $56-57^{\circ}$ (found: $\mathrm{C}, 73 \cdot 6 ; \mathrm{H}, 7 \cdot 15 ; \mathrm{N}, 5.52$ per cent; $\mathrm{C}_{15} \mathrm{H}_{17} \mathrm{O}_{2} \mathrm{~N}$ requires $\mathrm{C}, 74 \cdot 1 ; \mathrm{H}, 7 \cdot 00 ; \mathrm{N}, 5 \cdot 76$ per cent), prepared by the reduction of dianisyl ketoxime. The freshly prepared dianisylcarbinyl nitrite and the decomposition products obtained by heating the ester in chloroform solution at $100^{\circ}$ yielded no amine on reduction; but when the ester was kept in glacial acetic acid solution containing a trace of hydrochloric acid at $0^{\circ} \mathrm{C}$. for $12 \mathrm{hr}$. and the products reduced, $7 \cdot 2$ per cent of amine was isolated as the crystalline benzoyl derivative.

Since no amine was isolated on reduction of the freshly prepared nitrite, it is concluded that in those experiments where dianisylmethylamine was isolated isomerization to dianisylnitromethane had occurred.

J. KENYON

Chemistry Department,

Battersea Polytechnic,

London, S.W.11.

Nov. 17.

I Keogi and Chowdhurl, J. Chem. Soc., 109, 701 (1916).

${ }^{2}$ Keogi and Chowdhuri, J. Chem. Soc., 111, 899 (1917).

' Levy and Rose, Quart. Rev. Chem. Soc., 1, 359 (1947).

- Arcus, Balfe and Kenyon, J. Chem. Soc., 485 (1938).

\section{An Oxidation Involving the Hydroxyl Cation, $(\mathrm{OH})^{+}$}

A shorT time ago we reported ${ }^{1}$ that hypobromous acid became a powerful brominating agent in the presence of mineral acids owing to the production of bromine cations :

$\mathrm{H}^{+}+\mathrm{HOBr} \rightleftharpoons \mathrm{H}_{2} \mathrm{O}+\mathrm{Br}^{+}\left(\right.$or $\left.\left(\mathrm{H}_{2} \mathrm{OBr}\right)^{+}\right)$.

It therefore seemed possible that hydrogen per. oxide might react similarly with mineral acids to give hydroxyl cations, $(\mathrm{OH})^{+}$, or $\left(\mathrm{H}_{3} \mathrm{O}_{2}\right)^{+}$, and, indeed, Evans and Uri ${ }^{2}$ have computed that the equilibrium constant for the reaction

$$
\mathrm{H}^{+}+\mathrm{HO}-\mathrm{OH} \rightleftharpoons\left(\mathrm{H}_{2} \stackrel{+}{\mathrm{O}}-\mathrm{OH}\right)\left(\rightarrow \mathrm{H}_{2} \mathrm{O}+\mathrm{OH}^{+}\right)
$$

should have a value of the order of $10^{3}$; thus in $10 \mathrm{~N}$ acid solution hydrogen peroxide should be about I per cent converted into the active cation, $(\mathrm{OH})^{+}$.

Evidence of cationoid substitution by the $(\mathrm{OH})^{+}$ cation confirms that these hypotheses are correct, and there can now be no doubt that hydrogen peroxide can oxidize aromatic compounds in the presenoe of strong mineral acids, though not in aqueous or acetic acid solutions. When hydrogen peroxide is added to an aqueous solution of benzene, there is no apparent reaction ; but when concentrated sulphuric acid is poured as a layer below this mixture, then the boundary is at once marked by a brownish. black ring of oxidized material. Since phenols are much more easily substituted than benzene, hydroxylation by $(\mathrm{OH})^{+}$tends to produce highly oxidized. products. However, by taking mesitylene (I) and hydrogen peroxide in acetic acid-sulphuric acid mixtures, we have been able to show: (a) that the consumption of hydrogen peroxide is an acidcatalysed process, and (b) that mesitol (II) is a major reaction product. The faot that mesitol is already substituted in all ortho and para positions to the hydroxyl group prevents its destruction by further rapid hydroxylation.

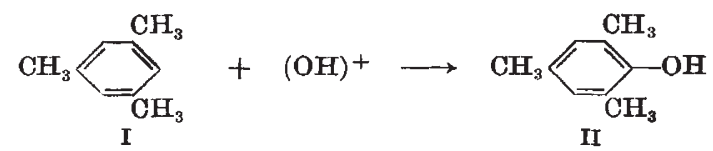

Hitherto it has been suggested tentatively ${ }^{8,4}$ that the epoxidation of olefins by perbenzoic and peracetic acids may involve a positively polarized hydroxyl group, that is, $\mathrm{AcO}-\mathrm{O}-{ }_{-}-\mathrm{OH}$; but no simple reaction diagnostic of the hydroxyl cation has hitherto been described. The conception of hydroxylation by the $(\mathrm{OH})^{+}$cation in acid media immediately affords a simple explanation of many oxidations which involve the addition of oxygen to a lone pair of electrons to give products containing dative bonds ; for example :

$$
\begin{aligned}
& R_{3} \mathrm{~N}: \rightarrow R_{3} \mathrm{~N} \rightarrow \mathrm{O} ; R-\mathrm{I} \rightarrow R-\mathrm{I} \rightarrow \mathrm{O} ; \\
& R-\mathrm{N}=\mathrm{N}-R^{\prime} \rightarrow R-\underset{+}{-\mathrm{N}}=\mathrm{N}-R^{\prime} ; R_{2} \ddot{\mathrm{S}}: \rightarrow R_{2} \ddot{\mathrm{S}} \rightarrow \mathrm{O}
\end{aligned}
$$

and has significant implications in connexion with many other oxidation processes. Among the reactions of hydrogen peroxide itself, we now may recognize oxidations due to $(a)$ the $(\mathrm{OH})^{+}$cation, $(b)$ the $(\cdot \mathrm{OH})$ neutral radical and $(c)$ the $(\mathrm{O}-\mathrm{OH})^{-}$anion. Each of these has well-defined characteristics, and it is not difficult to discriminate between them.

$$
\text { D. H. Derbyshire }
$$

Dyson Perrins Laboratory,

$$
\text { W. A. WATERS }
$$

Oxford.

Nov. 5.

${ }^{1}$ Derbyshire and Waters, Nature, 164, 446 (1949).

2 Evans, M. G., and Uri, N., Trans. Farad. Soc., 45, 224 (1949).

${ }^{3}$ Swern, D., Chemical Reviews, 45, 1, (1949).

4 Swern, D., J. Amer. Chem. Soc, 69, 1692 (1947).

\section{Bicholestatriene}

IN an attempt to find a now route to 7 -dehydrocholesterol (provitamin $\mathrm{D}_{3}$ ), a coloured steroid was encountered which is believed to be a bicholestatriene. A brief description of this compound is given here pending further details.

The starting matorial is $\Delta^{6}-i$-cholestadiene (I) prepared from $i$-cholesteryl methyl ether ${ }^{1}$. (I) was brominated with $\mathrm{N}$-bromosuccinimide (Ziegler reagent) ${ }^{2}$ in carbon tetrachloride, using a trace of benzoyl peroxide as a catalyst. 'The bromine atom entering at $\mathrm{C}_{8}$ is easily removed as hydrogen bromide giving $\Delta^{6,8(2)} i$-cholestatriene (II), and the liberated acid tends to cause the rearrangement of the $i$-steroid to the normal structure. Many reagents (potassium acetate, diethyl aniline, calcium carbonate or barium carbonate) were used with varying degrees of success 